\title{
Fermentative hydrogen production from glucose and starch using pure strains and artificial co-cultures of Clostridium spp.
}

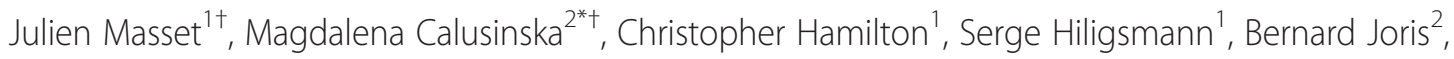
Annick Wilmotte ${ }^{2}$ and Philippe Thonart ${ }^{1}$

\begin{abstract}
Background: Pure bacterial strains give better yields when producing $\mathrm{H}_{2}$ than mixed, natural communities. However the main drawback with the pure cultures is the need to perform the fermentations under sterile conditions. Therefore, $\mathrm{H}_{2}$ production using artificial co-cultures, composed of well characterized strains, is one of the directions currently undertaken in the field of biohydrogen research.

Results: Four pure Clostridium cultures, including C. butyricum CWBI1009, C. pasteurianum DSM525, C. beijerinckii DSM1820 and C. felsineum DSM749, and three different co-cultures composed of (1) C. pasteurianum and C. felsineum, (2) C. butyricum and C. felsineum, (3) C. butyricum and C. pasteurianum, were grown in $20 \mathrm{~L}$ batch bioreactors. In the first part of the study a strategy composed of three-culture sequences was developed to determine the optimal pH for $\mathrm{H}_{2}$ production (sequence 1); and the $\mathrm{H}_{2}$-producing potential of each pure strain and co-culture, during glucose (sequence 2) and starch (sequence 3 ) fermentations at the optimal pH. The best $\mathrm{H}_{2}$ yields were obtained for starch fermentations, and the highest yield of $2.91 \mathrm{~mol} \mathrm{H}_{2} / \mathrm{mol}$ hexose was reported for $\mathrm{C}$. butyricum. By contrast, the biogas production rates were higher for glucose fermentations and the highest value of $1.5 \mathrm{~L}$ biogas/ $\mathrm{h}$ was observed for the co-culture (1). In general co-cultures produced $\mathrm{H}_{2}$ at higher rates than the pure Clostridium cultures, without negatively affecting the $\mathrm{H}_{2}$ yields. Interestingly, all the Clostridium strains and cocultures were shown to utilize lactate (present in a starch-containing medium), and C. beijerinckii was able to reconsume formate producing additional $\mathrm{H}_{2}$. In the second part of the study the co-culture (3) was used to produce $\mathrm{H}_{2}$ during 13 days of glucose fermentation in a sequencing batch reactor (SBR). In addition, the species dynamics, as monitored by qPCR (quantitative real-time PCR), showed a stable coexistence of C. pasteurianum and C. butyricum during this fermentation.
\end{abstract}

Conclusions: The four pure Clostridium strains and the artificial co-cultures tested in this study were shown to efficiently produce $\mathrm{H}_{2}$ using glucose and starch as carbon sources. The artificial co-cultures produced $\mathrm{H}_{2}$ at higher rates than the pure strains, while the $\mathrm{H}_{2}$ yields were only slightly affected.

Keywords: Clostridium spp., Fermentative $\mathrm{H}_{2}$ production, qPCR

\footnotetext{
* Correspondence: mcalusinska@ulg.ac.be; calusinska@wp.pl

${ }^{\dagger}$ Equal contributors

${ }^{2}$ Centre for Protein Engineering, Bacterial physiology and genetics, University

of Liège, Allée de la Chimie 3, Liège, B4000, Belgium

Full list of author information is available at the end of the article
} 


\section{Background}

Hydrogen is regarded as a future energy vector for transportation and stationary power. However, its current production is heavily dependent on fossil fuels, yielding globally $40 \%$ of $\mathrm{H}_{2}$ from steam reforming of methane and another $48 \%$ from crude oil and coal. By contrast, biohydrogen production offers a sustainable alternative and by utilizing renewable carbon resources can be considered as a $\mathrm{CO}_{2}$ offset [1].

Hydrogen can be produced biologically by four different processes: direct and indirect biophotolysis, photofermentation and dark fermentation. Fermentative hydrogen production not only provides higher gas production rates compared to photosynthetic processes, but is also light independent and can utilize various carbon sources, including wastewaters [2].

Many agricultural and food-industry wastes and wastewaters contain large quantities of carbohydrates and proteins. However, their complex nature can adversely affect their digestibility for the fermentative organism(s) present in a $\mathrm{H}_{2}$ producing bioreactor [3]. Naturally occurring microbial consortia derived from different sources, such as compost, anaerobic sludge or soil, are frequently used for $\mathrm{H}_{2}$ production. On one hand due to the metabolic flexibility, provided by the different members of the community, they are vital to the waste treatment systems, as they can tolerate different substrates and environmental conditions [4]. On the other hand the same metabolic flexibility can undermine the $\mathrm{H}_{2}$ production efficiency by initiating and sustaining other metabolic pathways, e.g. increased lactate formation by lactic acid bacteria [5]. Additionally it has been shown that within a complex and poorly defined population, bacterial successions can occur even within a batch culture, and that this can significantly impact $\mathrm{H}_{2}$ production $[6,7]$.

In comparison to the use of natural, mixed bacterial populations, pure strain cultures were shown to produce $\mathrm{H}_{2}$ at higher yields [8]. However, the main drawback of the use of pure cultures is the necessity to maintain the fermentations under sterile conditions. In fact the autochthonous bacteria present in the waste materials can easily overgrow the pure strain used to produce $\mathrm{H}_{2}$ in a bioreactor. Therefore, the use of artificial microbial cocultures and consortia, composed of pre-defined and well characterized species, has attracted particular interest in the developing biohydrogen industry. Co-cultures can perform complex functions, such as simultaneous pentose or hexose consumption, which generally cannot be performed by a single species [9]. Being potentially more robust to changes in environmental conditions, microbial co-cultures can resist periods of nutrient limitation better; what is typically combined with the exchange of metabolites between the different bacteria
[10]. Another feature is biomass concentration with the formation of aggregates, which occurs more readily in co-cultures than with a single strain culture [11]. However, until now, the creation of a stable artificial community composed of three or more members has been problematic due to the diverse rates of growth of the different members and the subsequent imbalance between the consumption and production of metabolites [12]. To date, a stable coexistence of community members over a long period of time has only been reported for a few $\mathrm{H}_{2}$ producing artificial consortia and co-cultures [13-16].

Therefore this study has two goals. The first is to characterize $\mathrm{H}_{2}$ production by four Clostridium strains (C. beijerinckii DSM 1820, C. butyricum CWBI 1009, C. pasteurianum DSM 525 and C. felsineum DSM 794) grown as pure cultures with different substrates. The second goal is to develop stable $\mathrm{H}_{2}$ producing co-cultures composed of two different Clostridium spp. A simple three-step approach, consisting of three fermentation sequences, was used to first assess the optimal $\mathrm{pH}$ for $\mathrm{H}_{2}$ production for pure strains and for co-cultures with glucose (sequence 1). Then the potential of the pure cultures and co-cultures to stably produce $\mathrm{H}_{2}$ using different carbon sources was evaluated by performing glucose (sequence 2) and starch fermentations (sequence 3) at a controlled optimal $\mathrm{pH}$. In order to assess the metabolic interactions between the different strains, the metabolites produced were monitored by HPLC. The potential of the co-culture, composed of C. butyricum and C. pasteurianum (co-culture 3), to grow consistently and produce $\mathrm{H}_{2}$ was also evaluated during a 13-day glucose fermentation in a sequencing batch bioreactor (SBR). The dynamics of the two strains was monitored throughout the fermentation using a previously optimized qPCR assay based on quantification of the $\operatorname{rec} A$ and gyrA marker genes [17].

\section{Results and Discussion}

In the first part of this study a strategy of three-culture sequences was developed to characterize hydrogen production by four pure Clostridium strains (C. beijerinckii DSM 1820, C. butyricum CWBI 1009, C. pasteurianum DSM 525 and C. felsineum DSM 794), and three cocultures composed of two closely related clostridia; i.e. co-culture (1) with C. pasteurianum and C. felsineum, co-culture (2) with C. butyricum and C. felsineum, and co-culture (3) with C. pasteurianum and C. butyricum. Two strains, namely $C$. butyricum and C. beijerinckii, have been widely investigated for $\mathrm{H}_{2}$-production in bioreactors and they were shown to ferment a variety of different carbon sources, including pure sugars (e.g. glucose, starch, sucrose, galactose [18-22] palm oil [23] yeast wastes [24] or sugar cane juice [25]. C. pasteurianum has been often detected as a dominant strain in 
sludge-derived $\mathrm{H}_{2}$-producing mixed cultures [26]. By contrast the application of C. felsineum for $\mathrm{H}_{2}$ production has not yet been reported.

The hydrogen production potential of the pure strains and co-cultures was evaluated in the same 20 L SBRs. The first sequence was conducted without $\mathrm{pH}$ control using glucose as a carbon source. By monitoring the hydrogen production rate for each pure strain and coculture, the optimal $\mathrm{pH}$ for $\mathrm{H}_{2}$ production was determined. The second and the third sequences were carried out at optimal $\mathrm{pH}$ values, using either glucose or starch as fermentative substrates.

Additionally in the second part of the study, co-culture (3) with C. pasteurianum and C. butyricum, was used to produce hydrogen over a longer period (13 days) in a SBR, maintained at fixed $\mathrm{pH}$ using glucose as the carbon source.

Single batch fermentation to evaluate the optimal $\mathrm{pH}$ for $\mathrm{H}_{2}$ production (Sequence 1)

$\mathrm{pH}$ is considered as one of the key factors affecting $\mathrm{H}_{2}$ production and metabolic pathways in Clostridium spp. $[20,21,27]$. Therefore during the first sequence with glucose the optimal $\mathrm{pH}$ for $\mathrm{H}_{2}$ production was determined for the pure strains and for the co-cultures. Previously the optimal $\mathrm{pH}$ for $\mathrm{H}_{2}$ production was determined by comparing the $\mathrm{H}_{2}$ yields obtained in different batch fermentations (multi-stage fermentation approach) performed at different fixed $\mathrm{pH}$ values [21,27]. However, this method is time consuming and requires several batch fermentations in order to increase accuracy. In our study the optimal $\mathrm{pH}$ of the medium was defined in a single glucose batch fermentation with the initial $\mathrm{pH}$ of the medium adjusted to 7.3. Due to the production of acidic metabolites, mainly formate, lactate, acetate and butyrate, the $\mathrm{pH}$ of the medium decreased progressively reaching $4.8 \pm 0.2$ at the end of the fermentation. The decreasing $\mathrm{pH}$ of the medium triggered $\mathrm{H}_{2}$ production. The optimal $\mathrm{pH}$ was defined as the $\mathrm{pH}$ value at which the biogas production rate reached a maximum (Table 1). This approach also made it possible to determine the lower inhibiting $\mathrm{pH}$ value at which hydrogen production ceased completely.

The optimal $\mathrm{pH}$ values defined for $C$. butyricum, $C$. felsineum and C. pasteurianum were similar, on average $5.35 \pm 0.15$. This $\mathrm{pH}$ value is similar to the optimal $\mathrm{pH}$ of 5.5 observed for the best $\mathrm{H}_{2}$ production by $C$. butyricum EB6 [28]. By contrast the optimal pH for C. beijerinckii was $\mathrm{pH} 6.7$ (Table 1). Furthermore, its $\mathrm{H}_{2}$ production was inhibited at $\mathrm{pH}$ 5.2, which overlaps with the optimal $\mathrm{pH}$ values for the three other Clostridium strains selected. Therefore, due to its very different $\mathrm{pH}$ requirements, $C$. beijerinckii was not used in any of the three two-strain co-cultures. Additionally, this species has
Table 1 Optimal pH ranges for $\mathrm{H}_{2}$ production by pure Clostridium strains and co-cultures determined during one-stage glucose fermentation (first sequence) at unregulated $\mathbf{p H}$

\begin{tabular}{lcc}
\hline Strain/ co-culture & \multicolumn{2}{c}{ pH value } \\
\cline { 2 - 3 } & Optimal & Inhibitory \\
\hline C. beijerinckii DSM 1820 & 6.7 & 5.2 \\
C. butyricum CWBI 1009 & 5.15 & 4.7 \\
C. pasteurianum DSM 525 & 5.4 & 4.6 \\
C. felsineum DSM 794 & 5.5 & 5 \\
Co-culture 1 & 5.3 & 4.7 \\
Co-culture 2 & 5.3 & 4.6 \\
Co-culture 3 & 5.3 & 5.0 \\
\hline
\end{tabular}

been shown to inhibit the growth of other bacteria, including the Clostridium species analysed in this study (data not shown), probably by producing bacteriocin and circularin A [16].

In order to validate the data obtained, we performed a comparison between the optimal pH values for $\mathrm{H}_{2}$ production determined for C. butyricum CWBI 1009 and for C. pasteurianum DSM 525 by using a previously described multi-stage fermentation approach (Figure 1A and 1B) [21]. Finally the optimal $\mathrm{pH}$ values determined for the two strains with the two different approaches were similar; $r$ indicating that the new single batch fermentation approach provides a fast and accurate means of determining the optimal $\mathrm{pH}$ for $\mathrm{H}_{2}$ production.

To determine the optimal $\mathrm{pH}$ for each co-culture, the same single batch fermentation approach was used. For all three co-cultures the optimal $\mathrm{pH}$ for $\mathrm{H}_{2}$ production with glucose was 5.3 (Table 1). The inhibiting $\mathrm{pH}$ values for co-cultures (1) with C. pasteurianum and C. felsineum and (2) with C. butyricum and C. felsineum were found to be 4.7 and 4.6, respectively. However for coculture (3) with C. butyricum and C. pasteurianum, the inhibiting $\mathrm{pH}$ of 5.0 was very close to the optimal one (5.3). Therefore, use of this co-culture in large bioreactors, in which significant $\mathrm{pH}$ variations occur, would require care to avoid inhibition of $\mathrm{H}_{2}$ production due to a small shift in $\mathrm{pH}$ [29]. A narrow optimal $\mathrm{pH}$ range for $\mathrm{H}_{2}$ production had already been suggested in previous studies, which reported that even small $\mathrm{pH}$ variations caused a shift in the metabolic pathways leading to a reduction in the final $\mathrm{H}_{2}$ yield [21,30].

\section{Metabolites and $\mathrm{H}_{2}$ production during glucose batch fermentations with unregulated $\mathrm{pH}$ (Sequence 1)}

Clostridia metabolize glucose to pyruvate via the glycolysis pathway (Figure 2). Subsequently, pyruvate is converted to lactate and acetyl-CoA. The latter reaction is driven either by pyruvate:formate lyase (PFL) resulting 

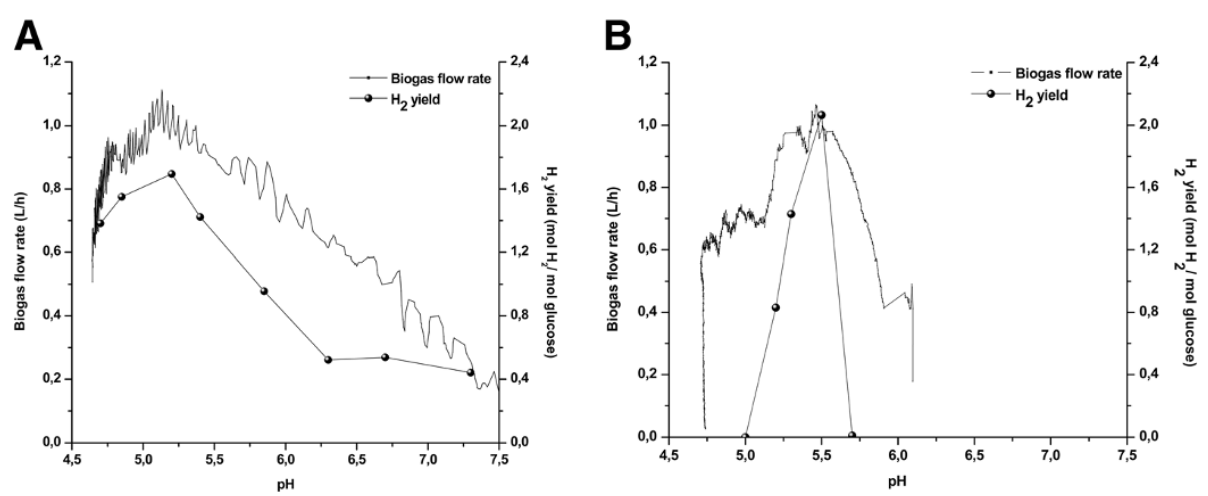

Figure 1 Comparison of a single-batch fermentation approach (monitoring the biogas flow rate) versus a multi-stage fermentation approach (monitoring the $\mathrm{H}_{2}$ yield obtained at different $\mathrm{pH}$ values) to evaluate the optimal $\mathrm{pH}$ for $\mathrm{H}_{2}$ production. (A)-C. butyricum; (B)-C. pasteurianum.

in formate production, or by pyruvate:ferredoxin oxidoreductase (PFOR) with co-generation of reduced ferredoxin (Fd). Reduced $\mathrm{Fd}$ is an electron donor for hydrogenases, which are the $\mathrm{H}_{2}$-generating enzymes [31]. Both pathways lead to acetyl-CoA that can be further converted mainly to butyrate, acetate and ethanol. Therefore, it can be assumed that the hydrogen production rate will be affected when high levels of formate are produced, since no reduced Fd is generated.

Comparing the pure strains and the co-cultures, there was a significant variation in the pattern of the fermentation metabolites obtained during glucose batch fermentations with unregulated $\mathrm{pH}$ conditions (Table 2). The glucose fermentations resulted primarily in the production of formate for the pure strains of $C$. felsineum $(12.14 \mathrm{mM})$ and formate (18.48 $\mathrm{mM})$ and butyrate $(16.58 \mathrm{mM})$ for $C$. butyricum. High production of both formate and butyrate was also characteristic for co-culture (2) with $C$. butyricum and C. felsineum (13.44 $\mathrm{mM}$ and $11.25 \mathrm{mM}$ ) and co-culture (3) with C. butyricum and C. pasteurianum $(8.00 \mathrm{mM}$ and $9.12 \mathrm{mM})$. Acetate molar concentrations were similar for the pure cultures of $C$. butyricum and $C$. pasteurianum (10.01 $\pm 0.81 \mathrm{mM})$ and for the three co-cultures $(8.89 \pm 0.47 \mathrm{mM})$; suggesting that during unregulated $\mathrm{pH}$ fermentation acetate production may be a common path for ATP synthesis [34]. By contrast, for pure $C$. beijerinckii and $C$. felsineum strains acetate was the metabolite with the lowest yield

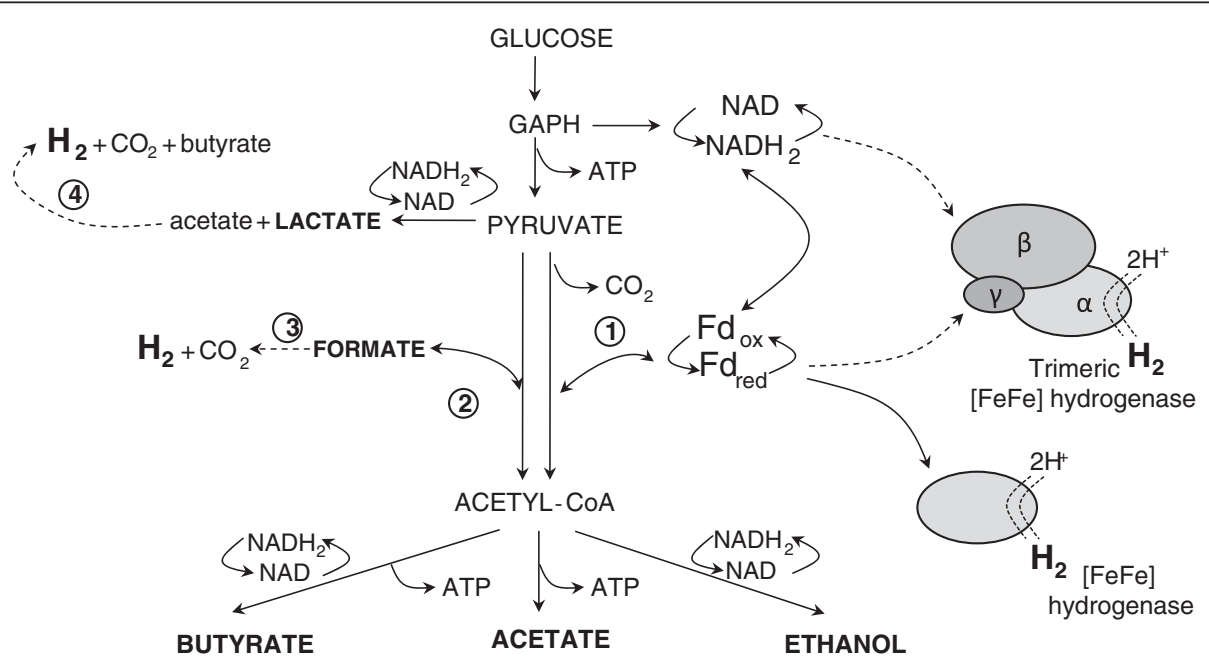

Figure 2 A simplified overview of the main metabolic pathways involved in $\mathbf{H}_{\mathbf{2}}$ production by Clostridium spp. Dashed lines indicate hypothetical pathways. 1-PFOR, 2-PFL, 3-[FeFe] TR(M2) hydrogenase [32], 4-pathway proposed by Matsumoto et al., [33], Fd ox/red-ferredoxin oxidized/reduced. 
Table 2 Fermentation end products (molar concentrations) obtained during glucose fermentation at unregulated pH (first sequence)

\begin{tabular}{|c|c|c|c|c|c|c|}
\hline Strain/co-culture & $\begin{array}{l}\text { Formate } \\
(\mathrm{mM})\end{array}$ & $\begin{array}{l}\text { Lactate } \\
\text { (mM) }\end{array}$ & $\begin{array}{l}\text { Acetate } \\
(\mathrm{mM})\end{array}$ & $\begin{array}{l}\text { Butyrate } \\
\text { (mM) }\end{array}$ & $\begin{array}{c}\mathrm{H}_{2} \text { yield } \\
\text { (mol } \mathrm{H}_{2} / \mathrm{mol} \\
\text { glucose) }\end{array}$ & $\begin{array}{l}\text { Biogas production } \\
\text { rate }(L \text { biogas } / h)^{a}\end{array}$ \\
\hline $\begin{array}{l}\text { C. beijerinckii } \\
\text { DSM } 1820\end{array}$ & 3.92 & 5.28 & 3.15 & 8.33 & 1.45 & 0.38 \\
\hline $\begin{array}{l}\text { C. butyricum } \\
\text { CWBI } 1009\end{array}$ & 18.48 & 3.44 & 9.20 & 16.58 & 0.97 & 0.34 \\
\hline $\begin{array}{l}\text { C. pasteurianum } \\
\text { DSM } 525\end{array}$ & 0.57 & 12.78 & 10.82 & 7.65 & 0.66 & 1.03 \\
\hline C. felsineum DSM 794 & 12.14 & 0.61 & 3.61 & 1.80 & 0.62 & 0.93 \\
\hline Co-culture 1 & 3.09 & 11.81 & 8.45 & 3.89 & 1.61 & 0.92 \\
\hline Co-culture 2 & 13.44 & 1.79 & 9.55 & 11.25 & 1.02 & 1.02 \\
\hline Co-culture 3 & 8.0 & 3.61 & 8.67 & 9.12 & 1.33 & 1.4 \\
\hline
\end{tabular}

${ }^{\mathrm{a}}$ Maximum biogas production rate.

$(3.38 \pm 0.23 \mathrm{mM})$. For C. pasteurianum as well as for co-culture (1), with C. pasteurianum and C. felsineum, the product composition changed yielding higher amounts of lactate $(12.78 \mathrm{mM}$ and $11.81 \mathrm{mM}$ for the pure strain and the co-culture, respectively) and lower amounts of formate $(0.57 \mathrm{mM}$ and $3.09 \mathrm{mM}$ for the pure strain and the co-culture, respectively). Surprisingly, co-culture (1) also provided the highest $\mathrm{H}_{2}$ yield (Table 2), despite the fact that lactate is the most unfavourable by-product, since it drains away electrons required for $\mathrm{H}_{2}$ production [35]. On one hand it was suggested that the activation of lactate production could be an additional catabolic pathway, enabling the bacterium to cope with the excesses of carbon and NADH produced during the GAPDH step (glyceraldehyde 3-phosphate dehydrogenase; Figure 2) of glycolysis [36]. On the other hand it had already been demonstrated that under different conditions, e.g. with iron limitation, C. pasteurianum fermented glucose to lactate without affecting $\mathrm{H}_{2}$ production, mainly at the expense of butyrate [37]. As stated above, C. pasteurianum produced lactate as the main metabolite, while its butyrate production was $9 \%$ and $54 \%$ lower than that for $C$. beijerinckii and $C$. butyricum, respectively (Table 2). Similarly, co-culture (1) with C. pasteurianum and $C$. felsineum produced the lowest amount of butyrate $(3.90 \mathrm{mM})$ and its lower formate production and increased $\mathrm{H}_{2}$ yield could suggest that pyruvate was converted to acetyl-CoA via the PFOR pathway, rather than via PFL (Figure 2). By contrast, despite the high molar concentrations of acetate and butyrate, commonly associated with higher $\mathrm{H}_{2}$ yields [38], the $\mathrm{H}_{2}$ yields obtained for culture (2) with $C$. butyricum and C. felsineum and culture (3) with $C$. butyricum and C. pasteurianum were lower (Table 2); due to the preferential formation of acetyl-CoA by the PFL enzyme, as could be expected given the increased formate production.

\section{Metabolites and $\mathrm{H}_{2}$ production during glucose batch fermentations at fixed optimal $\mathrm{pH}$ (Sequence 2)}

After the first sequence, in which the correct $\mathrm{pH}$ was determined for each pure strain and co-culture, $3 \mathrm{~L}$ of the medium (i.e. $15 \%$ of the working volume) were replaced with the same amount of fresh MDT medium containing glucose at a final concentration of $5 \mathrm{~g} / \mathrm{L}$. During this sequence the optimal $\mathrm{pH}$ for each pure strain and co-culture was kept constant (Table 1). The C. butyricum CWBI 1009 strain provided the highest $\mathrm{H}_{2}$ yield of $2.1 \mathrm{~mol} \mathrm{H}_{2} / \mathrm{mol}$ glucose. However, the maximum biogas production rate $(0.42 \mathrm{~L}$ of biogas $/ \mathrm{h})$ was significantly lower than that for the other three pure strain cultures (Table 3). Interestingly, a strong inversely proportional correlation between biogas production rates and $\mathrm{H}_{2}$ yields was observed for the pure Clostridium strains (Figure 3). The corresponding increase in $\mathrm{H}_{2}$ yield with decreasing biogas production rate can be explained by the lower $\mathrm{H}_{2}$ partial pressure in the fermentation medium, as previously discussed by other authors [18,39]. Additionally, high $\mathrm{H}_{2}$ partial pressure has been shown to have an inhibitory effect on hydrogenases, with a metabolic shift towards the production of other reduced metabolites, e.g. lactate, ethanol or formate [40]. Accordingly, C. felsineum, which provided the highest biogas production rate and the lowest yield during glucose fermentation at fixed $\mathrm{pH}$, also produced the highest levels of lactate and formate (Table 3 ).

Maintaining the culture at fixed optimal $\mathrm{pH}$ gave rise to a $10 \%$ increase in the $\mathrm{H}_{2}$ yield compared to unregulated $\mathrm{pH}$ conditions for co-culture (1) with C. pasteurianum and C. felsineum, and provided an increase of as 
Table 3 Fermentation end products (molar concentrations) obtained during glucose fermentation performed at fixed optimal pH values (second sequence)

\begin{tabular}{lcccccc}
\hline Strain/ co-culture & $\begin{array}{c}\text { Formate } \\
(\mathbf{m M})\end{array}$ & $\begin{array}{c}\text { Lactate } \\
(\mathbf{m M})\end{array}$ & $\begin{array}{c}\text { Acetate } \\
(\mathbf{m M})\end{array}$ & $\begin{array}{c}\text { Butyrate } \\
(\mathbf{m M})\end{array}$ & $\begin{array}{c}\mathbf{H}_{2} \text { yield } \\
\left(\mathbf{m o l ~ H}_{\mathbf{2}} / \mathbf{m o l}\right. \\
\text { glucose) }\end{array}$ & $\begin{array}{c}\text { Biogas production } \\
\text { rate }(\mathrm{L} \text { biogas/ h) }\end{array}$ \\
\hline C. beijerinckii DSM 1820 & 1.69 & -1.85 & 4.48 & 16.99 & 1.88 & 0.55 \\
C. butyricum CWBI 1009 & -0.05 & 2.74 & 11.44 & 17.13 & 2.10 & 0.42 \\
C. pasteurianum DSM 525 & 8.66 & 4.17 & 11.24 & 11.39 & 1.19 & 0.90 \\
C. felsineum DSM 794 & 4.29 & 23.42 & 3.08 & 4.49 & 0.88 & 1.14 \\
Co-culture 1 & 0.21 & 4.73 & 6.20 & 5.73 & 1.71 & 1.50 \\
Co-culture 2 & 0.74 & 4.18 & 8.95 & 10.76 & 1.62 & 1.10 \\
Co-culture 3 & 0.93 & 4.57 & 7.25 & 8.46 & 2.12 & 1.46 \\
\hline
\end{tabular}

${ }^{a}$ Maximum biogas production rate.

much as $60 \%$ for co-cultures (2) and (3) (C. butyricum \& C. felsineum and C. butyricum \& C. pasteurianum, respectively) (Table 3 ). The $2.12 \mathrm{~mol}_{2} / \mathrm{mol}$ glucose yield obtained by co-culture 3 was comparable to the results obtained for C. butyricum grown separately, but the coculture 3 biogas production rate was 1.6 and 3.5 fold higher than that obtained with the pure C. pasteurianum and C. butyricum strains, respectively (Table 3 ).

Compared to the previous sequence, the composition of the fermentation end products changed radically for both the pure strains and for the three co-cultures, yielding on average a higher proportion of acetate and butyrate in the total soluble metabolites, when the $\mathrm{pH}$ was fixed at the optimal value (Table 3). For $C$. beijerinckii, C. butyricum and C. pasteurianum the production of lactate decreased significantly, while for $C$. felsineum it increased. The increased lactate production, observed for co-culture (1) with C. pasteurianum and $C$. felsineum during the previous batch glucose fermentation with unregulated $\mathrm{pH}$, was no longer present and the three co-cultures produced similar amounts of lactate (4.49 $\pm 0.23 \mathrm{mM}$ ) during this fermentation sequence. A decrease in formate production, ranging from 8 to 18 fold, was observed at fixed $\mathrm{pH}$ for co-cultures (3) with C. butyricum and C. pasteurianum, and (2) with C. butyricum and $C$. felsineum. Additionally, the increased $\mathrm{H}_{2}$ yield for the three co-cultures suggested that pyruvate was mainly metabolized to acetyl-CoA via PFOR (Figure 2).

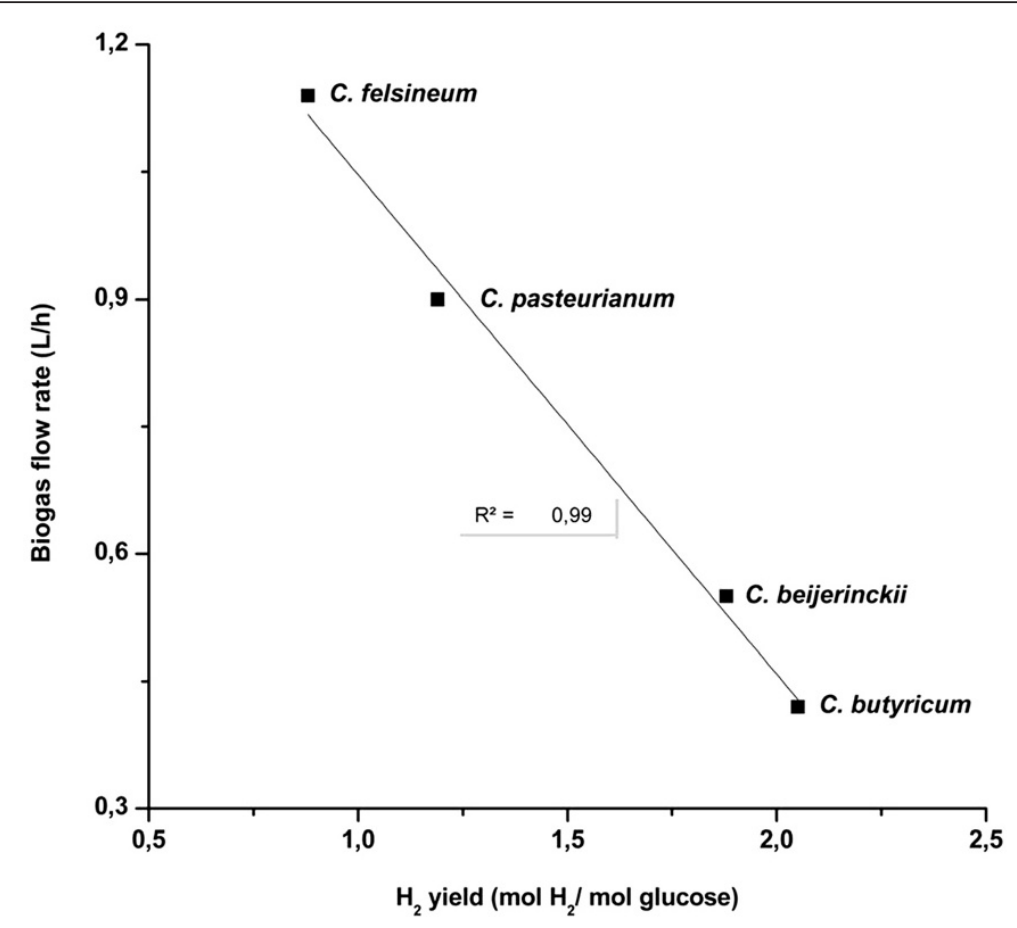

Figure 3 Inversely proportional relation between $\mathrm{H}_{2}$ yield and production rate for pure Clostridium cultures. 


\section{Metabolites and $\mathrm{H}_{2}$ production during starch batch fermentations at fixed optimal pH (Sequence 3)}

Simple sugars, e.g. glucose or lactose, are the preferred carbon sources for $\mathrm{H}_{2}$ producing fermentative bacteria, due to their fast biodegradability [20,22,41]. However, pure carbohydrates are far too expensive for use as feedstock and renewable waste material is therefore an attractive potential alternative for the sustainable production of hydrogen [3,42]. Consequently, during the third fermentation sequence with removal/addition of $3 \mathrm{~L}$ of the MDT medium, the ability of the pure Clostridium strains and the co-cultures to grow on different carbon sources was further assessed using starch $(5 \mathrm{~g} /$ $\mathrm{L}$ ), which is present at high levels in many food industry and agricultural wastes.

Pure C. butyricum and C. pasteurianum cultures consumed respectively $62.8 \%$ and $57.4 \%$ of the starch initially added to the medium (after $46.5 \mathrm{~h} \pm 1$ ). These results seem to contradict the findings of Chen et al., where the authors had to employ a starch pre-treatment step in order to accelerate hydrogen production [43]. In their work C. pasteurianum (different indigenous isolates from Taiwan) was reported to be unable to use starch, neither for the cell growth nor $\mathrm{H}_{2}$ production.

Of the other two pure strains, C. beijerinckii consumed merely $13.4 \%$ of the starch after $71 \mathrm{~h}$ of fermentation, and C. felsineum was unable to use starch as a fermentative carbon source. By contrast with these results, another strain of $C$. beijerinckii, namely $C$. beijerinckii AM21B isolated from termites, was reported to efficiently consume starch with concomitant production of $\mathrm{H}_{2}$ [44].

By contrast with the pure strain cultures, starch was shown to be easily degraded by the three co-cultures and was entirely consumed after $47.5 \mathrm{~h} \pm 0.5$ by co-culture (1) with C. pasteurianum and C. felsineum and by co-culture (3) with C. butyricum and C. pasteurianum, without the need for any pre-treatment such as acid or enzymatic hydrolysis. Co-culture (2) with C. butyricum and C. felsineum required $70 \mathrm{~h}$ of fermentation to consume all the starch, probably due to a lower hydrolysis rate.

For the pure strains the biogas production rates were lower than those obtained during the previous glucose fermentation sequence, probably due to the lower biodegradability of starch and the additional hydrolysis step necessary to release the fermentable sugars. As a result, the resulting $\mathrm{H}_{2}$ partial pressure may have been lower, thus favouring higher $\mathrm{H}_{2}$ yields, which increased by an average of $44 \% \pm 6$ for C. butyricum and C. pasteurianum. Even though $C$. beijerinckii did not consume significant amounts of starch the strain was shown to produce $\mathrm{H}_{2}$, using both formate and lactate produced during the previous glucose fermentation sequences (Table 4). Also, even if C. felsineum was unable to consume any starch, it nevertheless produced $\mathrm{H}_{2}$ during this fermentation sequence, mainly from the lactate present in the medium. The ability of these bacteria to reconsume formate and lactate indicates the existence of new metabolic pathways in clostridia (Figure 2, indicated by dashed line). It opens new perspectives for a better substrate utilization, resulting in increased hydrogen production rates and/or yield [45].

E. coli and other Enterobacteriaceae can produce hydrogen from formate by the action of an enzymatic complex called formate:hydrogen lyase (FHL). However, none of the Clostridium strains studied has been shown to possess this type of enzyme. Surprisingly, another putative trimeric [FeFe] hydrogenase complex has been found in the genome of $C$. beijerinckii and it seems to be associated with a formate dehydrogenase-like protein [32]. This could explain the ability of C. beijerinckii to utilise formate for $\mathrm{H}_{2}$ production. However the enzyme activity has never been studied in this strain. A similar enzymatic complex was reported for Eubacterium acidaminophilum, and indeed the bacterium was shown to couple formate oxidation to $\mathrm{H}_{2}$ production [46].

In case of the co-cultures, the highest $\mathrm{H}_{2}$ yield of $2.32 \mathrm{~mol} \mathrm{H}_{2}$ / mol hexose was obtained for co-culture (3) with $C$. butyricum and C. pasteurianum. Interestingly, the yield obtained for $C$. butyricum grown as a pure strain culture on starch was higher $\left(2.91 \mathrm{~mol} \mathrm{H}_{2} / \mathrm{mol}\right.$ hexose), but the biogas production rate tripled when the strain was combined with $C$. pasteurianum in a co-culture (Table 4). A comparison of the $\mathrm{H}_{2}$ yields obtained during glucose and starch sequences showed that, for starch, the $\mathrm{H}_{2}$ yields were higher for co-culture (1) with C. pasteurianum and C. felsineum, and co-culture (3) with C. butyricum and C. pasteurianum, probably due to the lower biogas production rates and the resulting lower $\mathrm{H}_{2}$ partial pressure, as was shown for the pure strains. Indeed, the biogas production rates during the starch batch fermentations ranged from 0.95 (co-culture 1) to 1.3 (co-culture 2) L biogas/ h, and except for the co-culture (2) they were $30 \%$ lower compared to the previous glucose batch fermentation.

Recently Quéméneur et al. showed, by performing a series of $\mathrm{H}_{2}$-producing batch fermentations, that both the carbohydrate chain length and alpha- or beta-linkage have an impact on $\mathrm{H}_{2}$ production [47]. In their work the $\mathrm{H}_{2}$ yields decreased from 1.84 (fructose fermentation) to $1.38 \mathrm{~mol} \mathrm{H}_{2} / \mathrm{mol}$ hexose (maltotriose fermentation) with the increasing chain length of the substrate. By contrast, the three co-cultures used in our study were characterized by equal or even higher $\mathrm{H}_{2}$ yields when grown on a polysaccharide (starch) compared to a monosaccharide (glucose). However different experimental conditions were applied in the two studies and the use of $500 \mathrm{ml}$ glass bottles without $\mathrm{pH}$ control 
Table 4 Fermentation end products (molar concentrations) obtained during the starch fermentation performed at fixed optimal pH values (third sequence)

\begin{tabular}{|c|c|c|c|c|c|c|}
\hline Strain/co-culture & $\begin{array}{l}\text { Formate } \\
(\mathrm{mM})\end{array}$ & $\begin{array}{l}\text { Lactate } \\
(\mathrm{mM})\end{array}$ & $\begin{array}{l}\text { Acetate } \\
(\mathrm{mM})\end{array}$ & $\begin{array}{c}\text { Butyrate } \\
\text { (mM) }\end{array}$ & $\begin{array}{c}\mathrm{H}_{2} \text { yield } \\
\text { (mol } \mathrm{H}_{2} / \mathrm{mol} \\
\text { hexose) }\end{array}$ & $\begin{array}{l}\text { Biogas production } \\
\text { rate }(\mathrm{L} \text { biogas } / \mathrm{h})^{\mathrm{a}}\end{array}$ \\
\hline C. beijerinckii DSM 1820 & -4.34 & -3.18 & 1.25 & 4.0 & $\mathrm{~b}$ & 0.28 \\
\hline C. butyricum CWBI 1009 & 0.09 & -0.91 & 4.21 & 8.63 & 2.91 & 0.35 \\
\hline C. pasteurianum DSM525 & 4.96 & -10.63 & 2.62 & 10.22 & 1.79 & 0.42 \\
\hline C. felsineum DSM 794 & 3.77 & -28.62 & 8.98 & 1.04 & b & 0.24 \\
\hline Co-culture 1 & 1.06 & -14.47 & 0.12 & 6.76 & 2.08 & 0.95 \\
\hline Co-culture 2 & -0.42 & -4.08 & 3.19 & 14.08 & 1.6 & 1.3 \\
\hline Co-culture 3 & 9.04 & -6.49 & 8.22 & 17.81 & 2.32 & 1.05 \\
\hline
\end{tabular}

${ }^{a}$ Maximum biogas production rate.

b This strain produced $\mathrm{H}_{2}$ mainly from the lactate and/or formate present in the medium, therefore it was not possible to correctly calculate the $\mathrm{H}_{2}$ yield per mole of hexose consumed.

versus $20 \mathrm{~L}$ batch reactors operating at fixed $\mathrm{pH}$ may explain the differences in findings.

From the fermentation end-product analysis several observations can be made about the different strains' and co-cultures' metabolisms during the starch batch fermentation. A radical decrease in acetate production by a factor of 2.7 and 4.3 was found for pure strains of C. butyricum and C. pasteurianum, respectively (Table 4). Butyrate production was also shown to be lower for $C$. beijerinckii and C. butyricum, but it did not change significantly for C. pasteurianum. By contrast for the cocultures fermenting starch a 1.3- and 2.1-fold increase in butyrate production was observed for co-cultures (2) with $C$. butyricum and C. felsineum, and (3) with $C$. butyricum and $C$. pasteurianum, compared to the previous batch sequence with glucose. At the same time the amount of acetate produced from starch decreased 2.5fold and as much as 50-fold for co-cultures (2) with $C$. butyricum and $C$. felsineum and (1) with $C$. pasteurianum and $C$. felsineum, respectively. Interestingly the lactate produced during the former batch sequences with glucose was consumed in this step by the pure strains and by the three co-cultures. The highest rates of lactate consumption were observed for co-cultures (1) and (3), suggesting that $C$. pasteurianum may have been the main lactate consumer. Indeed this strain consumed the highest amounts of lactate during the starch fermentation stage when grown as a pure strain culture (Table 4).

Typical lactate consuming species, e.g. Clostridium propionicum, produces propionic and acetic acids together with $\mathrm{CO}_{2}$ during lactate fermentation, but no $\mathrm{H}_{2}$ is generated via this pathway [48]. However the lactic acid present in a starch containing medium, undergoes a different, not completely understood metabolic pathway, resulting in $\mathrm{H}_{2}$ production together with the formation of butyrate as the major metabolite [49]. Recently, Matsumoto and co-authors proposed a similar pathway, where one mol of acetate reacted with two moles of lactate giving in turn $\mathrm{H}_{2}, \mathrm{CO}_{2}$ and butyrate as the main products [33]. Indeed a radical decrease in molar acetate concentration was characteristic for the pure strains and the three co-cultures grown on starch, compared to the previous glucose fermentation stage (Table 4).

Longer-term evaluation of $\mathrm{H}_{2}$ production using co-culture (3) with $C$. butyricum and C. pasteurianum and a glucose substrate in a SBR at fixed $\mathbf{p H} \mathbf{5 . 3}$

As shown above, the Clostridium strains analysed in this study, when combined into two-strain artificial cocultures, proved capable of producing $\mathrm{H}_{2}$ at significantly higher rates without negatively affecting the final $\mathrm{H}_{2}$ yield. Therefore, to further evaluate their $\mathrm{H}_{2}$ producing abilities, co-culture (3) was used as a model culture, since it had been shown to combine the best $\mathrm{H}_{2}$ yield and biogas production rate, during the glucose batch fermentation under controlled $\mathrm{pH}$ conditions. The co-culture was grown over a longer period of time (13 days), by extending the operating mode to 7 sequences. The fermentation was carried out at the fixed optimal $\mathrm{pH}$ value of 5.3, using glucose as a carbon source.

A series of experiments involved 7 sequences of removal/ addition of $12 \%$ ( $2 \mathrm{~L}$ ) of the MDT medium, ensuring a glucose concentration of $5 \mathrm{~g} / \mathrm{L}$ after each removal/ addition. The sequences followed the initial batch culture and each sequence was started after the complete consumption of the previously added glucose. The biogas production rates and $\mathrm{H}_{2}$ yields were calculated for each sequence (Figure 4A), and the $\mathrm{H}_{2}$ content of the biogas was estimated to be between 62 and $65 \%$. The biogas production rate measured during the first sequence was similar to that recorded during the batch glucose fermentation at fixed pH (1.45 L biogas/ h; Table 3). However, it was decreasing progressively and reached $0.8 \mathrm{~L} / \mathrm{h}$ at the end of sequence 4 (Figure 4A). During the last three sequences the biogas production rate stabilized at 


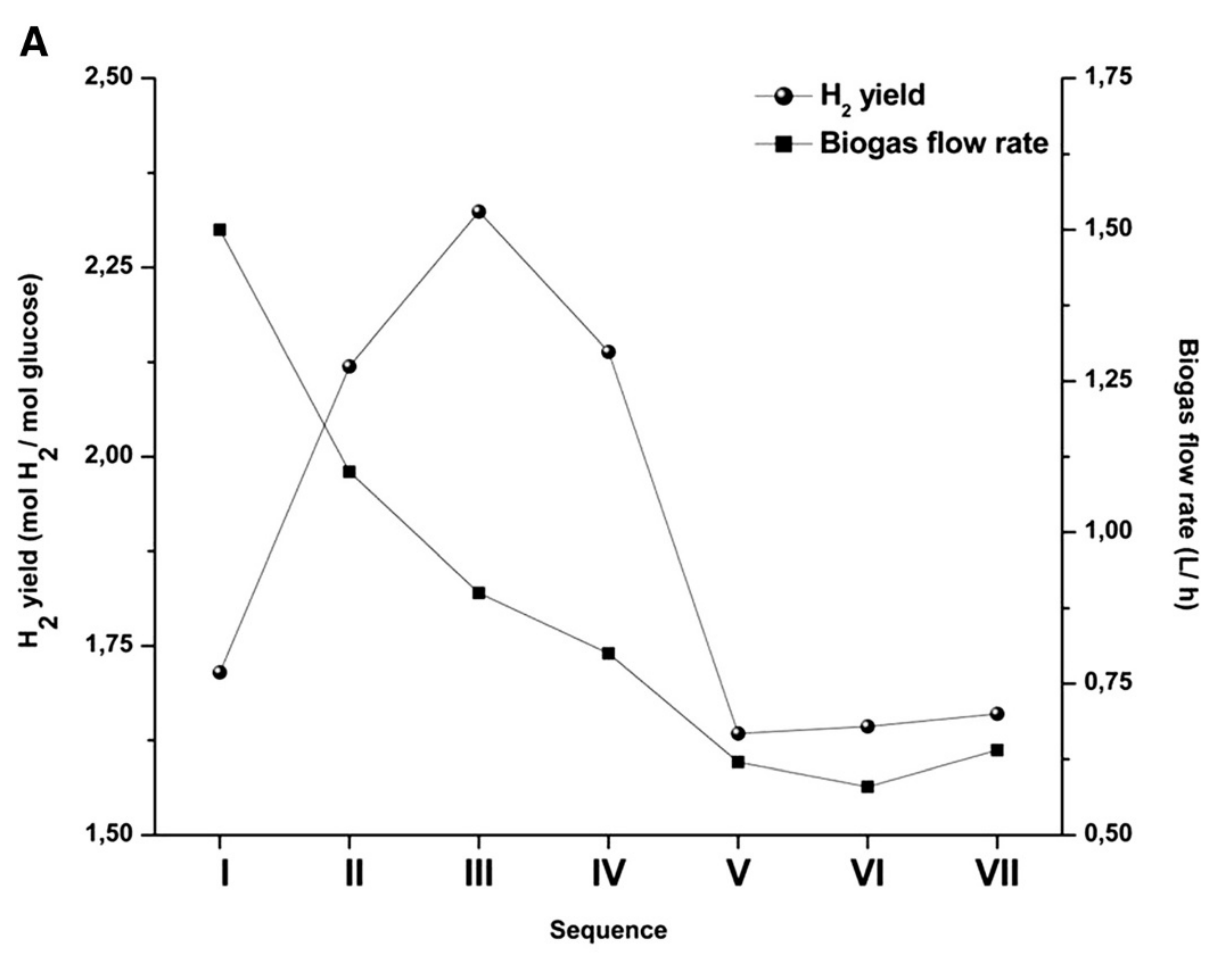

B

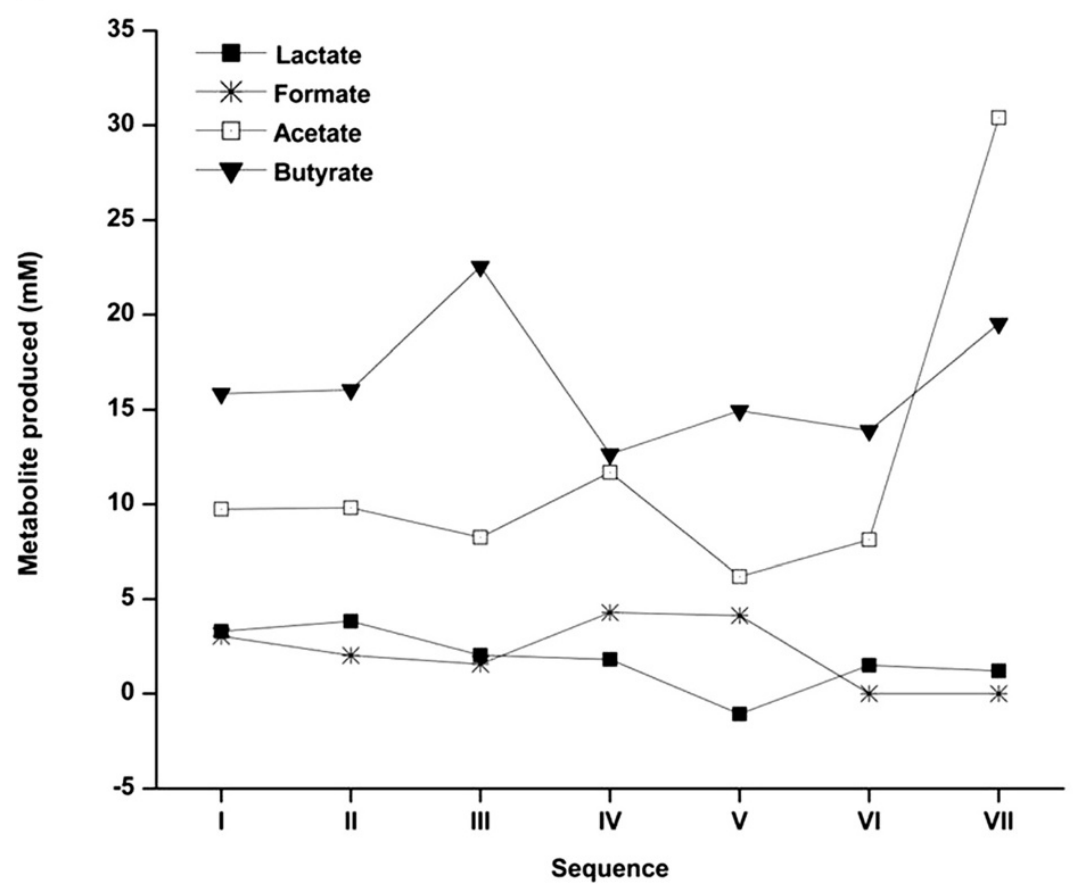

Figure 4 Hydrogen yields and production rates (A) and fermentation end products (B) obtained for co-culture (3) with C. butyricum and $C$. pasteurianum during a 13-day glucose fermentation in a SBR. 
$0.6 \mathrm{~L} / \mathrm{h}$. This decrease was probably due to the inhibitory effect of the accumulation of volatile fatty acids (VFAs, mainly butyrate and acetate), which was $5 \pm 0.46$ fold higher at the end of the experiment than at the end of the first batch sequence. Acetate and butyrate represented $95.4 \%$ of the total VFAs present in the medium at the end of sequence 7 , with minor amounts of lactate detected $(4.6 \%$ of the VFAs). The production of the fermentative metabolites was similar to that for the previous batch glucose fermentation at controlled $\mathrm{pH}$ for the same coculture (Figure 4B, Table 3). Formate was produced at low rates $(3 \mathrm{mM} \pm 1.09)$ and only during the first five sequences. Ethanol production was not detected. The distribution of the metabolites confirmed the relationship between high hydrogen yield and butyrate formation. The $\mathrm{H}_{2}$ yield increased from 1.71 to $2.32 \mathrm{~mol} \mathrm{H}_{2} / \mathrm{mol}$ hexose during the first three sequences. It subsequently decreased after the fourth sequence and then stabilized at $1.63 \mathrm{~mol} \mathrm{H}_{2} / \mathrm{mol}$ hexose during the last three sequences. Similarly, during the first three sequences the molar concentration of butyrate increased from $15.85 \mathrm{mM}$ to $22.54 \mathrm{mM}$. When the hydrogen yield decreased after the fourth sequence the production of butyrate decreased to $12.64 \mathrm{mM}$. Similar correlation between the hydrogen yield and the production of butyrate had been previously observed [50,51]. However, such a correlation can only hold if the PFOR pathway dominates compared to the PFL pathway, generating higher amounts of the reduced $\mathrm{Fd}$ necessary for $\mathrm{H}_{2}$ production (Figure 2).

Although the maximal $\mathrm{H}_{2}$ yield obtained in this experiment represents less than $60 \%$ of the maximum theoretical yield that can be obtained by dark fermentation (4 mol $\mathrm{H}_{2} / \mathrm{mol}$ glucose), only a few studies have reported higher yields, sometimes using much more sophisticated and expensive systems [39]. For example, employing a two-stage process combining thermophilic starch hydrolysis and dark fermentation, Chen et al. obtained a yield of $2.4 \mathrm{~mol} \mathrm{H}_{2} / \mathrm{mol}$ hexose (reported as $13.2 \mathrm{mmol} \mathrm{H}_{2} /$ g glucose) for C. butyricum CGS2 [52]. In another study a $\mathrm{H}_{2}$ yield of $2.79 \mathrm{~mol} \mathrm{H}_{2} / \mathrm{mol}$ sucrose was reported for an acclimated, mesophilic sewage sludge grown in an anaerobic SBR [53]. Interestingly, when combining C. butyricum in a co-culture with immobilized cells of Rhodopseudomonas faecalis, a $\mathrm{H}_{2}$ yield of $4.134 \mathrm{~mol} \mathrm{H}_{2} / \mathrm{mol}$ glucose was reported [54]. This indicates that the development of a two stage system, combining an artificial co-culture composed of Clostridium spp. with a photosynthetic $\mathrm{H}_{2}$-producing bacterium, could additionally increase the final $\mathrm{H}_{2}$ yield over the theoretical maximum of $4 \mathrm{~mol}_{2} / \mathrm{mol}$ glucose that can be reached by clostridia.
Species dynamics for co-culture (3) with C. butyricum and C. pasteurianum monitored by $\mathrm{QPCR}$ during the 13 days of glucose fermentation in the SBR

A sequenced or a continuous operational mode for $\mathrm{H}_{2}$ production is necessary for its future industrial application [39]. However the behaviour and the genetic composition of a defined artificial co-culture can change over time, thus affecting the final $\mathrm{H}_{2}$ production.

Therefore, in addition to the fermentation characteristics, the species dynamics of co-culture (3), with C. butyricum and C. pasteurianum, was studied during the 13-day glucose fermentation in the SBR. This monitoring was carried out using a previously optimized qPCR approach [17], and targeting the recA and gyrA genes from $C$. butyricum and C. pasteurianum. The $\mathrm{qPCR}$ assays, carried out with samples taken during each sequence step (at the beginning and/ or at the end of each sequence), revealed clear changes in the quantitative composition and the dominance of the community members. When performing the qPCR with both $r e c A$ and $g y r A$ primer sets the amplification results were similar and comparable to each other (Figure 5A and $5 \mathrm{~B}$ ). At the time of the inoculation of the bioreactor (sequence 1) C. butyricum constituted $87.6 \% \pm 0.06$ of the coculture population, whereas C. pasteurianum was much less abundant $(12.39 \% \pm 0.06)$. However, C. pasteurianum had already become largely dominant after $19 \mathrm{~h}$ of incubation, accounting for $82 \% \pm 1.3$ of the population, while $C$. butyricum had declined to $17.86 \% \pm 1.3$. During the course of the experiment the number of $C$. pasteurianum cells present in the co-culture continued to increase. The highest proportion of $C$. butyricum was detected during the first four sequences when this species comprised $32.76 \% \pm 2.3$ of the co-culture. Surprisingly, the highest hydrogen yield of $2.32 \mathrm{~mol} \mathrm{H}_{2} / \mathrm{mol}$ glucose was also measured during the second sequence. The number of cells of C. butyricum started to decline slowly from the fifth sequence, representing only $6.13 \% \pm 0.05$ of the total population after 13 days.

In general, as shown by qPCR, both organisms coexisted in the co-culture and no species was completely displaced by the other, despite the fact that there was only one carbon source. A similar situation was previously observed for the two closely related Caldicellulospiruptor species, combined in a $\mathrm{H}_{2}$ producing co-culture and grown under nutrient limiting conditions [13]. C. saccharolyticus which was in a minority during the batch start-up phase (less than $5 \%$ of the total population), overgrew C. kristjanssonii during the glucose and mixed sugar fermentations. Nevertheless none of the species was completely washed out from the co-culture. The occurrence of (complex) interspecies interactions between the microorganisms is hypothesized to be a key factor enhancing their stable co-existence in a population [13]. It has been suggested that under nutrient limitation a minority species can become metabolically active, and that this activity can be crucial for the survival of the whole 


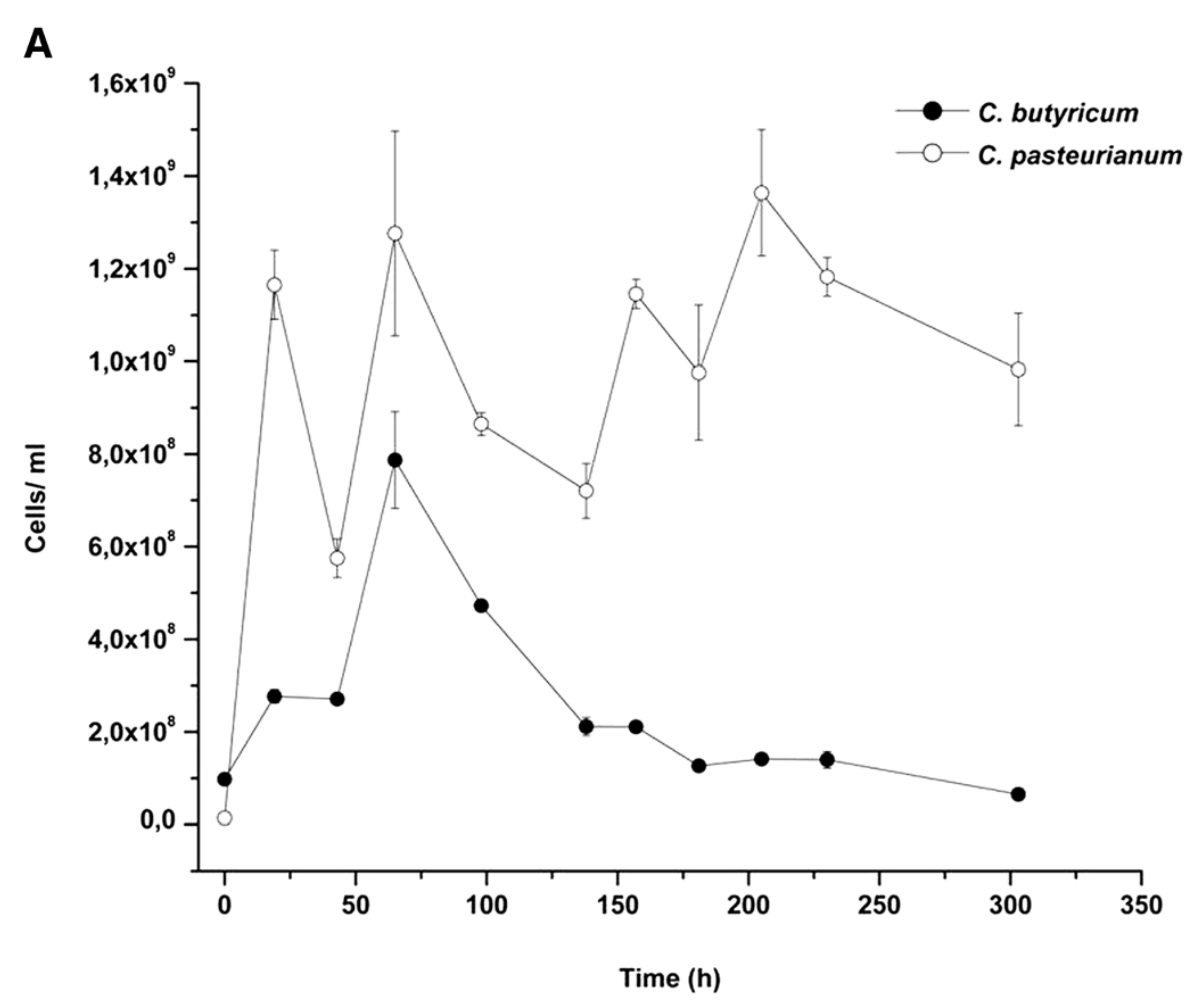

B

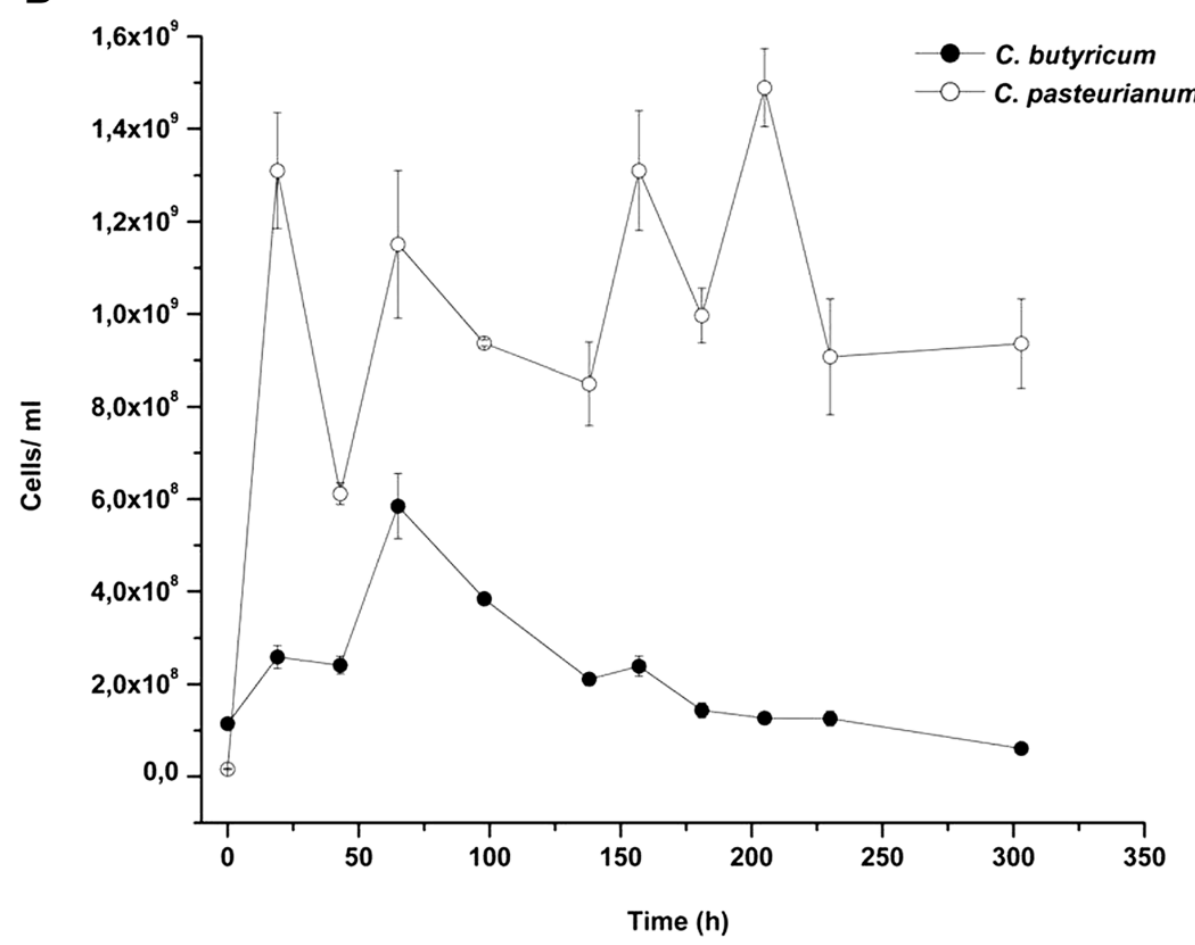

Figure 5 Structural dynamics of co-culture (3) with C. butyricum and C. pasteurianum during a 13-day glucose fermentation in a SBR. Cell numbers obtained from qPCR analysis based on recA (A) and gyrA (B) gene quantification. Sequence I (0-25 h), II (25-65 h), III (65-98 h), IV (98-138 h), V (138-181 h), VI (181-230 h), VII (230-303 h). 
population [10]. However further studies, including research on the species interactions and the metabolite trading between the bacterial members in a co-culture, are needed to better understand the behaviour of the different strains in a $\mathrm{H}_{2}$-producing artificial community.

\section{Conclusions}

Artificial co-cultures composed of different Clostridium species were shown to offer better performance in terms of efficient $\mathrm{H}_{2}$ production than the corresponding pure strain cultures. In contrast to the pure strain cultures, of which only C. butyricum and C. pasteurianum were able to partially hydrolyse starch, the three co-cultures completely consumed the starch without any need for pre-treatment. Surprisingly, all the Clostridium strains and co-cultures studied were shown to efficiently reconsume the lactate present in a starch-containing medium. Additionally, C. beijerinckii appeared to produce $\mathrm{H}_{2}$ by re-oxidizing the previously produced formate. The utilization of lactate and formate for $\mathrm{H}_{2}$ production by different Clostridium spp suggests the existence of novel pathways leading to $\mathrm{H}_{2}$ in this genus.

The hydrogen yields obtained in this study by mesophilic fermentation of glucose and starch were amongst the highest reported to date for Clostridium spp., cultured in a large lab-scale bioreactor $(20 \mathrm{~L})$. A comparison of the use of glucose or starch as a fermentation substrate resulted in contrasting data. Grown on starch the pure Clostridium cultures and the co-cultures provided higher yields compared to glucose fermentation. By contrast higher biogas production rates were reported when glucose was used as the carbon source.

Interestingly, co-culture (3), with C. butyricum and $C$. pasteurianum, produced $\mathrm{H}_{2}$ efficiently during 13 days of glucose fermentation in a SBR. Moreover both species coexisted stably in the co-culture during this time, despite the fact that there was only one carbon source available. Additionally, no species was completely displaced by the other, suggesting that positive interactions between the community members were at least as important as the simple competition for nutrients.

Future studies to improve substrate utilisation and metabolite trading should focus on the utilisation in $\mathrm{H}_{2}$ production of artificial co-cultures with increasing species complexity. In addition, the use of cellulose should be of prime interest since it would ensure the sustainability of the cheap carbon source. Therefore, the addition of a cellulose hydrolysing species, e.g. Clostridium cellulolyticum, to the co-culture should be considered.

\section{Methods}

\section{Bacterial strains and culture conditions}

The type strains of C. beijerinckii DSM 1820, C. pasteurianum DSM 525 and C. felsineum DSM 794 were purchased from DSMZ (Deutsche Sammlung von Mikroorganismen und Zellkulturen). C. butyricum CWBI 1009 was previously isolated from a hydrogen-producing sludge [21]. The strains were anaerobically maintained in MDT medium ( $5 \mathrm{~g}$ glucose, $5 \mathrm{~g}$ casein peptone, $0.5 \mathrm{~g}$ yeast extract, $1.2 \mathrm{~g}$ $\mathrm{KH}_{2} \mathrm{PO}_{4}, 5.1 \mathrm{~g} \mathrm{Na} \mathrm{HPO}_{4}, 0.5 \mathrm{~g} \mathrm{MgSO}_{4} \times 7 \mathrm{H}_{2} \mathrm{O}$ and 0.5 g L-cysteine) as previously described [17]. Before the bioreactor inoculation the strains were individually sub-cultured for $24 \mathrm{~h}$ at $30^{\circ} \mathrm{C}$ under nitrogen atmosphere in $5 \mathrm{~L}$ glass bottles filled with MDT medium and equipped with silicone tubing and gas filters for sterile liquid transfer and outlet gas sterilisation. To initiate a co-culture an equal volume (L) of the two respective strain cultures was used.

\section{Bioreactor setup and sampling}

All fermentations were carried out in MDT medium in a 20 L stainless steel tank bioreactor (Biolafite) equipped with a shaft with three Rushton impellers (four blades, diameter $100 \mathrm{~mm}$, height $20 \mathrm{~mm}$ ), 0.2 um gas filter, butyl septum and tubing for temperature regulation, gas inlet, gas outlet and medium removal/addition. After sterilization $\left(120^{\circ} \mathrm{C}, 20 \mathrm{~min}\right)$ glucose or starch (rice starch, BENEO-Remy) were added sterilely and the medium was purged with nitrogen. The medium was continuously stirred at $100 \mathrm{rpm}$ and the $\mathrm{pH}$ was maintained automatically at a given value using $3 \mathrm{~N} \mathrm{KOH}$ (except for the unregulated $\mathrm{pH}$ fermentation). Finally $1 \mathrm{~L}$ of each (co-) culture was added to give a final working volume of $18 \mathrm{~L}$. For the sequenced-batch mode after an initial growth in batch mode $2 \mathrm{~L}(3 \mathrm{~L})$ of the medium were removed and the bioreactor was fed with $2 \mathrm{~L}(3 \mathrm{~L})$ of fresh medium containing sufficient glucose to provide a final concentration of $5 \mathrm{~g} / \mathrm{L}$ in the bioreactor. Gas samples from the bioreactor headspace were regularly analysed. Culture samples were withdrawn to monitor the co-culture dynamics and analyse the metabolites. Cells were harvested by centrifugation at $13000 \mathrm{x}$ g for $1 \mathrm{~min}$ and the cell lysates were prepared as previously described [17]. The supernatant was further filtrated through a $0.2 \mu \mathrm{m}$ cellulose acetate filter (Minisart Sartorius) and analysed for sugar consumption and metabolite formation.

\section{Experimental procedure}

A three-step strategy was developed to characterize the hydrogen production of the pure strains and co-cultures with glucose and starch as alternative fermentative substrates. The first batch fermentation was carried out with unregulated $\mathrm{pH}$ and glucose at a final concentration of $5 \mathrm{~g} / \mathrm{L}$. The initial $\mathrm{pH}$ was set at 7.3 and was allowed to decrease progressively as acidic metabolites accumulated. The optimal $\mathrm{pH}$ was defined as the value corresponding to the maximum biogas production rate. During the next sequence $3 \mathrm{~L}$ of the medium were 
Table 5 qPCR specific primers used in this study

\begin{tabular}{|c|c|c|c|c|}
\hline Strain & Primer name and sequence $\left(5^{\prime} \rightarrow 3^{\prime}\right)$ & $A T^{a}\left({ }^{\circ} \mathrm{C}\right)$ & size (bp) & Accession number \\
\hline \multirow[t]{4}{*}{$\begin{array}{l}\text { C. butyricum } \\
\text { CWBl1009 }\end{array}$} & $\begin{array}{l}\text { RecA-butF } \\
\text { AAGCATTAGTGCGTTCTGGAG }\end{array}$ & \multirow[t]{2}{*}{60} & \multirow[t]{2}{*}{97} & \multirow[t]{2}{*}{ HQ433355 } \\
\hline & $\begin{array}{l}\text { RecA-butR } \\
\text { GAATCTCCCATTTCCCCTTC }\end{array}$ & & & \\
\hline & $\begin{array}{l}\text { GyrA-butF } \\
\text { AGCAATGGGTAGAACTGCATC }\end{array}$ & \multirow[t]{2}{*}{60} & \multirow[t]{2}{*}{95} & \multirow[t]{2}{*}{ HQ433358 } \\
\hline & $\begin{array}{l}\text { GyrA-butR } \\
\text { ATTCTTCGCCATCAACTGCT }\end{array}$ & & & \\
\hline C. pasteurianum & $\begin{array}{l}\text { RecA-pastF } \\
\text { CTCATGTGGGACTTCAAGCA }\end{array}$ & \multirow[t]{2}{*}{60} & \multirow[t]{2}{*}{150} & \multirow[t]{2}{*}{ HQ433356 } \\
\hline \multirow[t]{3}{*}{ DSM525 } & $\begin{array}{l}\text { RecA-pastR } \\
\text { CACCAGGTGTTGTTTCTGGA }\end{array}$ & & & \\
\hline & $\begin{array}{l}\text { GyrA-pastF } \\
\text { AATGCATCTGGGGTAAGAGG }\end{array}$ & \multirow[t]{2}{*}{57} & \multirow[t]{2}{*}{91} & \multirow[t]{2}{*}{ HQ433359 } \\
\hline & $\begin{array}{l}\text { GyrA-pastR } \\
\text { CCACAAGTACATCCTITCAACA }\end{array}$ & & & \\
\hline
\end{tabular}

${ }^{\mathrm{a}} \mathrm{AT}-\mathrm{PCR}$ annealing temperature $\left({ }^{\circ} \mathrm{C}\right)$.

replaced with the same volume of a fresh MDT medium containing glucose at a final concentration of $5 \mathrm{~g} / \mathrm{L}$. During this stage the $\mathrm{pH}$ was fixed at the optimal value by the automatic addition of sterile $1.5 \mathrm{~N} \mathrm{KOH}$. During the third sequence $3 \mathrm{~L}$ of the medium were replaced with the same volume of a fresh MDT medium containing starch at a final concentration of $5 \mathrm{~g}$ hexose/L. The $\mathrm{pH}$ was controlled during this stage. The determination of the optimal $\mathrm{pH}$ value by a multi-stage approach was performed as previously described [21].

\section{Analytical methods}

The flow rate of the biogas produced in the bioreactor headspace was continuously measured with a wet flow meter (Ritter Gas meter Drum type TG01) connected to a computer running Rigamo data acquisition software (V1.30-K1). The proportion of hydrogen gas was determined using a gas chromatograph (GC) (HewlettPackard 5890 Series II) fitted with a thermal conductivity detector (TCD) and a $30 \mathrm{~m} \times 0.32 \mathrm{~mm}$ GAS PRO GSC capillary column (Altech) in series with a $20 \mathrm{~m} \times 0.25 \mathrm{~mm}$ CarboPLOT P7 column (Chrompak). The temperatures of the injection, TCD chambers and the oven were maintained at $90^{\circ} \mathrm{C}, 110^{\circ} \mathrm{C}$ and $55^{\circ} \mathrm{C}$ respectively. Nitrogen was used as the carrier gas in the column at a flow rate of $20 \mathrm{~mL}$ min-1. The HPLC analysis was carried out using an Agilent 1110 series (HP Chemstation software) as previously described [21].

\section{qPCR analysis}

Sequences of species-specific primers targeting the $\operatorname{rec} A$ and gyrA genes of C. butyricum and C. pasteurianum were as previously described (Table 5), [17]. PCR amplification was carried out with a Mini Opticon (BioRad).
The DNA template was prepared as previously described [17]. For bacterial quantification $1 \mu \mathrm{l}$ of washed cell suspended in $\mathrm{TE}^{-4}$ buffer was added directly to the PCR mix, as described previously [17]. The total volume of the PCR mix was $25 \mu \mathrm{l}$. The qPCR reactions specific for recA, gyrA consisted of $1 \mathrm{X}$ PCR mix (ABsolute Blue QPCR SYBR ${ }^{\circledR}$ Green Fluorescein Mix, Thermo Scientific) and each primer (HPLC cleaned; Biomers, Germany) at a final concentration of $150 \mathrm{nM}$. The qPCR cycling conditions were as follows: initial denaturation at $95^{\circ} \mathrm{C}$ for 15 min followed by 40 cycles of denaturation at $95^{\circ} \mathrm{C}$ for $30 \mathrm{~s}$, annealing at $60 / 57^{\circ} \mathrm{C}$ for $30 \mathrm{~s}$ and elongation at $72^{\circ} \mathrm{C}$ for $30 \mathrm{~s}$. Each sample was analyzed in triplicate. No-template control was included in each run. The specificities of the amplifications were verified at the end of each qPCR reaction by performing the melting curve analysis. The standard curve was prepared as previously described [17]. The reaction efficiency was calculated as factor specific [55], using the equation: $\mathrm{E}=10^{-1 / \text { slope }}$ (Additional file 1: Table S1).

\section{Additional file}

Additional file 1: Details of the GPCR analysis.

\section{Abbreviations}

Cq: Threshold value; E: qPCR reaction efficiency; Fd: Ferredoxin; GAPDH: Glyceraldehyde 3-phosphate dehydrogenase; gyrA: DNA gyrase; PFL: Pyruvate:formate lyase; PFOR: Pyruvate:ferredoxin oxidoreductase; qPCR: Quantitative real-time PCR; recA: DNA recombinase; SBR: Sequencing batch reactor; VFA: Volatile fatty acids.

\section{Competing interests}

The authors declare that they have no competing interests. 


\section{Acknowledgements}

The research was funded by an ARC project (Action de Recherche Concertée, ARC-07/12-04), granted by a French Community of Belgium. AW is a Research Associate of the FRS-FNRS. JM was the recipient of a FRIA fellowship (Fonds de la Communauté Française de Belgique pour la Formation à la Recherche dans l'Industrie et l'Agriculture). We would like to thank Laurent Beckers from the University of Liège for a critical review of the manuscript and lan Hamilton for English correction.

\section{Author details}

'Walloon Centre of Industrial Biology, Boulevard du Rectorat 29, Liège, B4000, Belgium. ${ }^{2}$ Centre for Protein Engineering, Bacterial physiology and genetics, University of Liège, Allée de la Chimie 3, Liège, B4000, Belgium.

\section{Authors' contributions}

JM performed the fermentation experiments, analyzed the results and helped to draft the manuscript. MC carried out the molecular analysis, analyzed the results and wrote the manuscript. $\mathrm{CH}$ and AW helped to draft the manuscript and participated in the coordination of the study. BJ, SH and PT participated in the coordination of the study. All the authors read and accepted the final version of the manuscript.

\section{Received: 24 November 2011 Accepted: 22 May 2012}

Published: 22 May 2012

\section{References}

1. Brentner $L B$, Peccia J, Zimmerman JB: Challenges in developing biohydrogen as a sustainable energy source: implications for a research agenda. Environ Sci Technol 2010, 44:2243-2254.

2. Vardar-Schara G, Maeda T, Wood TK: Metabolically engineered bacteria for producing hydrogen via fermentation. Microb Biotechnol 2008, 1:107-125.

3. Kapdan IK, Kargi F: Bio-hydrogen production from waste materials. Enzym Microb Technol 2006, 38:569-582.

4. Agler MT, Wrenn BA, Zinder SH, Angenent LT: Waste to bioproduct conversion with undefined mixed cultures: the carboxylate platform. Trends Biotechnol 2011, 29:70-78.

5. Baghchehsaraee B, Nakhla G, Karamanev D, Margaritis A: Fermentative hydrogen production by diverse microflora. Int I Hydrogen Energ 2010, 35:5021-5027.

6. Koskinen PEP, Kaksonen AH, Puhakka JA: The relationship between instability of $\mathrm{H}_{2}$ production and compositions of bacterial communities within a dark fermentation fluidised-bed bioreactor. Biotechnol Bioeng 2007, 97:742-758.

7. Huang $Y$, Zong W, Yan X, Wang R, Hemme CL, Zhou J, Zhou Z: Succession of the bacterial community and dynamics of hydrogen producers in a hydrogen-producing bioreactor. Appl Environ Microbiol 2010, 76:3387-3390

8. Antonopoulou G, Ntaikou I, Gavala H, Skiadas I, Angelopoulos K, Lyberatos $\mathrm{G}$ : Biohydrogen production from sweet sorghum biomass using mixed acidogenic cultures and pure cultures of Ruminococcus albus. Global Nest J 2007, 9:144-151.

9. Eiteman $\mathrm{M}$, Lee $\mathrm{S}$, Altman E: A co-fermentation strategy to consume sugar mixtures effectively. J Biol Eng 2008, 2:3.

10. Brenner $K$, You L, Arnold F: Engineering microbial consortia: a new frontier in synthetic biology. Trends Biotechnol 2008, 26:483-489.

11. Hallenbeck PC, Ghosh D: Advances in fermentative biohydrogen production: the way forward? Trends Biotechnol 2009, 27:287-297.

12. Weibel DB: Building communities one bacterium at a time. Proc Natl Acad Sci 2008, 105:18075-18076.

13. Zeidan A, Radstrom P, van Niel E: Stable coexistence of two Caldicellulosiruptor species in a de novo constructed hydrogenproducing co-culture. Microb Cell Fact 2010, 9:102

14. de Vrije T, Bakker R, Budde M, Lai M, Mars A, Claassen P: Efficient hydrogen production from the lignocellulosic energy crop Miscanthus by the extreme thermophilic bacteria Caldicellulosiruptor saccharolyticus and Thermotoga neapolitana. Biotechnol Biofuels 2009, 2:12.

15. Waks Z, Silver PA: Engineering a synthetic dual-organism system for hydrogen production. Appl Environ Microbiol 2009, 75:1867-1875.

16. Chang JJ, Chou CH, Ho CY, Chen WE, Lay JJ, Huang CC: Syntrophic coculture of aerobic Bacillus and anaerobic Clostridium for bio-fuels and bio-hydrogen production. Int J Hydrogen Energ 2008, 33:5137-5146.
17. Savichtcheva O, Joris B, Wilmotte A, Calusinska M: Novel FISH and quantitative PCR protocols to monitor artificial consortia composed of different hydrogen-producing Clostridium spp. Int J Hydrogen Energ 2010, 36:7530-7542

18. Junghare M, Subudhi S, Lal B: Improvement of hydrogen production under decreased partial pressure by newly isolated alkaline tolerant anaerobe, Clostridium butyricum TM-9A: Optimization of process parameters. Int J Hydrogen Energ 2012, 37:3160-3168.

19. Skonieczny MT, Yargeau V: Biohydrogen production from wastewater by Clostridium beijerinckii: Effect of $\mathrm{pH}$ and substrate concentration. Int J Hydrogen Energ 2009, 34:3288-3294

20. Cai G, Jin B, Saint CP, Monis PT: Metabolic flux analysis of hydrogen production network by Clostridium butyricum W5: Effect of $\mathrm{pH}$ and glucose concentrations. Int J Hydrogen Energ 2010, 35:6681-6690.

21. Masset J, Hamilton C, Hiligsmann S, Beckers L, Franck F, Thonart P: Effect of $\mathrm{pH}$ on glucose and starch fermentation in batch and sequenced-batch mode with a recently isolated strain of hydrogen-producing Clostridium butyricum CWBI1009. Int J Hydrogen Energ 2010, 35:3371-3378.

22. Beckers L, Hiligsmann S, Hamilton C, Masset J, Thonart P: Fermentative hydrogen production by Clostridium butyricum CWBI1009 and Citrobacter freundii CWBI952 in pure and mixed cultures. Biotechnologie, Agronomie, Société et Environnement [BASE] 2010, 14:393-400.

23. Badiei M, Jahim J, Anuar N, Abdullah S, Su L, Kamaruzzaman M: Microbial community analysis of mixed anaerobic microflora in suspended sludge of ASBR producing hydrogen from palm oil mill effluent. Int J Hydrogen Energ 2012, 37:3169-3176.

24. Chou CH, Han CL, Chang JJ, Lay JJ: Co-culture of Clostridium beijerinckii L9, Clostridium butyricum M1 and Bacillus thermoamylovorans B5 for converting yeast waste into hydrogen. International Journal of Hydrogen Energy 2011, 36:13972-13983.

25. Pattra S, Sangyoka S, Boonmee M, Reungsang A: Bio-hydrogen production from the fermentation of sugarcane bagasse hydrolysate by Clostridium butyricum. Int J Hydrogen Energ 2011, 36:8697-8703.

26. Cheng $\mathrm{CH}$, Hsu SC, Wu CH, Chang PW, Lin CY, Hung CH: Quantitative analysis of microorganism composition in a pilot-scale fermentative biohydrogen production system. Int J Hydrogen Energ 2011, 36:1415314161.

27. Liu IC, Whang LM, Ren WJ, Lin PY: The effect of $\mathrm{pH}$ on the production of biohydrogen by clostridia: thermodynamic and metabolic considerations. Int J Hydrogen Energ 2011, 36:439-449.

28. Chong M-L, Rahim RA, Shirai Y, Hassan MA: Biohydrogen production by Clostridium butyricum EB6 from palm oil mill effluent. Int I Hydrogen Energ 2009, 34:764-771.

29. Amanullah A, McFarlane CM, Emery AN, Nienow AW: Scale-down model to simulate spatial pH variations in large-scale bioreactors. Biotechnol Bioeng 2001, 73:390-399.

30. Hamilton C, Hiligsmann S, Beckers L, Masset J, Wilmotte A, Thonart P: Optimization of culture conditions for biological hydrogen production by Citrobacter freundii CWBI952 in batch, sequenced-batch and semicontinuous operating mode. Int J Hydrogen Energ 2010, 35:1089-1098,

31. Vignais PM, Billoud B: Occurrence, classification, and biological function of hydrogenases: an overview. Chem Rev 2007, 107:4206-4272.

32. Calusinska M, Happe T, Joris B, Wilmotte A: The surprising diversity of clostridial hydrogenases: a comparative genomic perspective. Microbiol 2010, 156:1575-1588.

33. Matsumoto M, Nishimura Y: Hydrogen production by fermentation using acetic acid and lactic acid. J Biosci Bioeng 2007, 103:236-241.

34. Lee H-S, Krajmalinik-Brown R, Zhang H, Rittmann BE: An electron-flow model can predict complex redox reactions in mixed-culture fermentative bioH ${ }_{2}$ : microbial ecology evidence. Biotechnol Bioeng 2009, 104:687-697.

35. Wang $X$, Monis PT, Saint CP, Jin B: Biochemical kinetics of fermentative hydrogen production by Clostridium butyricum W5. Int I Hydrogen Energ 2009, 34:791-798.

36. Payot S, Guedon E, Gelhaye E, Petitdemange H: Induction of lactate production associated with a decrease in NADH cell content enables growth resumption of Clostridium cellulolyticum in batch cultures on cellobiose. Res Microbiol 1999, 150:465-473.

37. Dabrock B, Bahl H, Gottschalk G: Parameters affecting solvent production by Clostridium pasteurianum. Appl Environ Microbiol 1992, 58:1233-1239. 
38. Hafez H, Nakhla G, El Naggar MH, Elbeshbishy E, Baghchehsaraee B: Effect of organic loading on a novel hydrogen bioreactor. Int J Hydrogen Energ 2010, 35:81-92.

39. Jung KW, Kim DH, Kim SH, Shin HS: Bioreactor design for continuous dark fermentative hydrogen production. Biores Technol 2011, 102:8612-8620.

40. Angenent LT, Karim K, Al-Dahhan MH, Wrenn BA, Domíguez-Espinosa R: Production of bioenergy and biochemicals from industrial and agricultural wastewater. Trends Biotechnol 2004, 22:477-485.

41. Napoli F, Olivieri G, Russo ME, Marzocchella A, Salatino P: Continuous lactose fermentation by Clostridium acetobutylicum - assessment of acidogenesis kinetics. Biores Technol 2011, 102:1608-1614.

42. Fernandes BS, Peixoto G, Albrecht FR, del Saavedra Aguila NK, Zaiat M: Potential to produce biohydrogen from various wastewaters. Energ Sustain Develop 2010, 14:143-148.

43. Chen SD, Lee KS, Lo YC, Chen WM, Wu JF, Lin CY, Chang JS: Batch and continuous biohydrogen production from starch hydrolysate by Clostridium species. Int J Hydrogen Energ 2008, 33:1803-1812.

44. Taguchi F, hang JD, Takiguchi S, Morimoto M: Efficient hydrogen production from starch by a bacterium isolated from termites. $J$ Ferment Bioeng 1992, 73:244-245

45. Hallenbeck PC, Abo-Hashesh M, Ghosh D: Strategies for improving biological hydrogen production. Biores Technol 2012, 110:1-9.

46. Graentzdoerffer A, Rauh D, Pich A, Andreesen JR: Molecular and biochemical characterization of two tungsten- and selenium-containing formate dehydrogenases from Eubacterium acidaminophilum that are associated with components of an iron-only hydrogenase. Arch Microbiol 2003, 179:116-130.

47. Quéméneur M, Hamelin J, Benomar S, Guidici-Orticoni M, Latrille E, Steyer J, Trably E: Changes in hydrogenase genetic diversity and proteomic patterns in mixed-culture dark fermentation of mono-, di- and trisacharides. Int J Hydrogen Energ 2011, 36:11654-11665.

48. Fermentations. In The physiology and biochemistry of prokaryotes. Edited by White D. New York Oxford: Oxford University Press; 1995:278.

49. Baghchehsaraee B, Nakhla G, Karamanev D, Margaritis A: Effect of extrinsic lactic acid on fermentative hydrogen production. Int J Hydrogen Energ 2009, 34:2573-2579.

50. Karadag D, Puhakka JA: Effect of changing temperature on anaerobic hydrogen production and microbial community composition in an open-mixed culture bioreactor. Int J Hydrogen Energ 2010, 35:1095410959.

51. Khanal SK, Chen W-H, Li L, Sung S: Biological hydrogen production: effects of $\mathrm{pH}$ and intermediate products. Int J Hydrogen Energ 2004, 29:11231131.

52. Chen SD, Lo YC, Lee KS, Huang TI, Chang JS: Sequencing batch reactor enhances bacterial hydrolysis of starch promoting continuous biohydrogen production from starch feedstock. Int J Hydrogen Energ 2009, 34:8549-8557.

53. Lin $\mathrm{CY}$, Jo $\mathrm{CH}$ : Hydrogen production from sucrose using an anaerobic sequencing batch reactor process. J Chem Technol Biotechnol 2003 78:678-684.

54. Ding J, Liu B-F, Ren N-Q, Xing D-F, Guo W-Q, Xu J-F, Xie G-J: Hydrogen production from glucose by co-culture of Clostridium butyricum and immobilized Rhodopseudomonas faecalis RLD-53. Int J Hydrogen Energ 2009, 34:3647-3652.

55. Rasmussen R: Quantification on the lightcycler. Rapid cycle real-time PCR, methods and applications 2000, :21-34.

doi:10.1186/1754-6834-5-35

Cite this article as: Masset et al:: Fermentative hydrogen production from glucose and starch using pure strains and artificial co-cultures of Clostridium spp. Biotechnology for Biofuels 2012 5:35.

\section{Submit your next manuscript to BioMed Central and take full advantage of:}

- Convenient online submission

- Thorough peer review

- No space constraints or color figure charges

- Immediate publication on acceptance

- Inclusion in PubMed, CAS, Scopus and Google Scholar

- Research which is freely available for redistribution

Submit your manuscript at www.biomedcentral.com/submit 